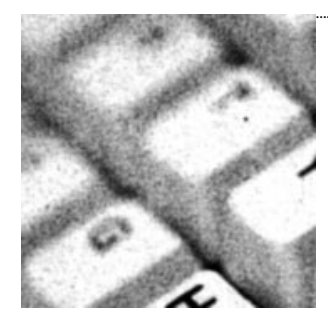

\title{
The web and its
}

\section{journalisms: considering}

the consequences of different types of newsmedia online

\section{MARK DEUZE} ASCoR, the Netherlands

\begin{abstract}
The internet - specifically its graphic interface, the world wide web - has had a major impact on all levels of (information) societies throughout the world. Specifically for journalism as it is practiced online, we can now identify the effect that this has had on the profession and its culture(s). This article defines four particular types of online journalism and discusses them in terms of key characteristics of online publishing - hypertextuality, interactivity, multimediality - and considers the current and potential impacts that these online journalisms can have on the ways in which one can define journalism as it functions in elective democracies worldwide. It is argued that the application of particular online characteristics not only has consequences for the type of journalism produced on the web, but that these characteristics and online journalisms indeed connect to broader and more profound changes and redefinitions of professional journalism and its (news) culture as a whole.
\end{abstract}

Key words

internet $\bullet$ journalism $\bullet$ multimedia $\bullet$ news $\bullet$ online

journalism 


\section{INTRODUCTION}

\section{Between the release of the world wide web (WWW) standard by}

CERN in 1991 and the database listing of almost 14,000 online news publications worldwide by US-based Editor \& Publisher Interactive (E\&P) in 2001, it is fair to say we are witnessing the end of the first decade of journalism online (Carlson, 2001; Medialinks, 2001). ${ }^{1}$ Pryor (2002) describes this period as the 'second wave' of online journalism, after a first wave of electronic publishing experiments (1982-92). In roughly 10 years, not only thousands of mainstream newsmedia have started websites (and quite a few of them have also closed these operations), but millions of individual users and special interest groups have used the internet as an outlet for their news as well (although such sites are not archived in mainstreamed databases such as E\&P). Correspondingly, trade and scholarly publications have focused extensively on journalism as it is produced online, which resulted in a sprawling field of research, handbooks and theories dealing with one or more aspects of online (cf. electronic, digital, wired) newsmedia production, especially focusing emerging new attitudes, skills and competencies for journalists (see overview articles, for example: Cooper, 1998; Deuze, 1998, 2001; Kawamoto, 1998; Singer, 1998; Pavlik, 1999; Kopper et al., 2000; Neuberger, 2000).

What seems to be missing, is a more or less condensed overview of the kinds of online journalism that have emerged during the first decade of the WWW, how these journalisms utilize the characteristics of the internet, and how these lessons learned may translate to the wider professional field, the discipline of journalism studies, and the concept of a journalistic or news culture. This article addresses these issues theoretically, basing its argument on a literature review, a range of published interviews with new media experts and online journalists in Europe and the United States, and an analysis of professional publications online (notably in the US: Online Journalism Review, Editor \& Publisher Interactive, including the Online News-mailing list; in Great Britain: dotJournalism; in the Netherlands: internetjournalist.nl, Planet Multimedia; in Germany:

Onlinejournalismus.de; Europe-wide: Europemedia.net). ${ }^{2}$ As this article aims to offer an overview, rather than a research report, references to specific data will be made in the context of other scholarly texts. In terms of the literature I particularly focus on handbooks and overviews of the field, as these can be seen as texts intended to address the full breadth of issues and concerns involved when 'doing' and 'studying' journalism online (annotated overviews and handbooks in this respect include: Callahan, 1998; Altmeppen et al., 2000; McGuire et al., 2000; De Wolk, 2001; Hall, 2001; Jager and Van Twisk, 2001; Pavlik, 2001; Reddick and King, 2001; Meier, 2002; Ward, 2002). ${ }^{3}$ 
As noted, the article consists of two main sections. First, four distinct online journalisms are discussed on a continuum ranging from purely editorial content to public connectivity-based websites (Odlyzko, 2001), a typology consisting of: [1] mainstream news sites, [2] index and category sites, [3] meta- and comment sites and [4] share and discussion sites (see Figure 1). These types of online journalism are analysed in terms of the defining characteristics of media production in an online environment: hypertextuality, interactivity and multimediality (Newhagen and Rafaeli, 1996; Bardoel and Deuze, 2001). In the second part of the article I aim to assess what the consequences of such new types of journalism may be for the existing journalistic culture in (Western) elective democracies with a functionally equivalent history of journalism professionalization (Deuze, 2002).

\section{ONLINE JOURNALISMS}

Before identifying different kinds of journalism online, one has to explicitly note that the internet - as it can be considered to affect journalism - can be discussed here in two ways: the inroads it has made into newsrooms and the desktops of journalists working for all media types in terms of ComputerAssisted Reporting (CAR); and how it has created its own professional type of news work: online journalism (Deuze, 1999). Using the internet as a reporting tool for 'traditional' media - all media except the internet - can be typified as the use and availability of searchable archives, databases and news sources on the internet by journalists. In many countries this reporting practice is still in its infancy as compared with, for example, the US

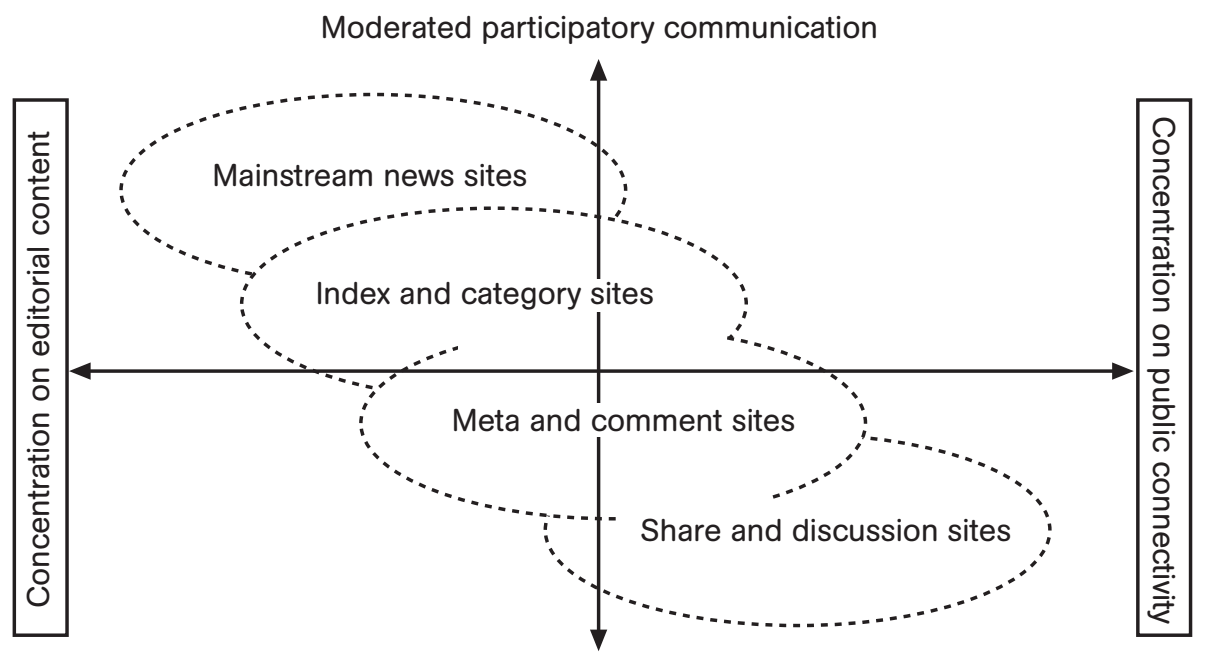

Unmoderated participatory communication

- Figure 1 A typology of online journalisms 
(Verwey, 2000). However, studies show convincingly that a vast majority of journalists in, for example, Southern Europe (for France, Spain and Italy see Hopscotch, 2002), the Netherlands (Pleijter et al., 2002), Germany (Luege, 1999; Luenenbuerger-Reidenbach et al, 2000), the US (Middleberg and Ross, 2002), and Australia (Quinn, 1998) are now using the internet regularly in their daily work. Several scholars have studied the effects of CAR and using the internet as a reporting tool for journalists and news work, concluding that beyond obvious benefits (more freely-available information, sources, checks and balances), many reporters and editors felt nervous and concerned about the 'omnipresence' of the internet in daily reporting (Singer, 1997a, 1997b), as well as the increased 'technical' element in newswork caused by it (Luenenbuerger-Reidenbach et al., 2000). For example, research at the $\mathrm{BBC}$ in the UK also revealed the unrest that new media technologies have created in the newsroom: journalists reported lack of time to adequately use and master the technology, feeling stressed because of the 'immediate' nature of the internet (Cottle, 1999). Another aspect related to CAR which affects all journalists is how to deal with online communication such as email, posts in newsgroups, and messages in ICQ and Internet Relay Chat (IRC) in an environment where the verification of information is extremely difficult due to the often anonymous, fast-paced communication involved (Porteman, 1999; Garrison, 2000). Several studies indeed signal the fact that the introduction of the internet in reporting has sped up the news process, sometimes even causing journalists to spend more time at their desks instead of going 'out on the street' (Pleijter et al., 2002: 28).

In this article, online journalism is seen as journalism as it is produced more or less exclusively for the world wide web (as the graphic interface of the internet). Online journalism can be functionally differentiated from other kinds of journalism by using its technological component as a determining factor in terms of a (operational) definition. The online journalist has to make decisions as to which media format or formats best convey a certain story (multimediality), consider options for the public to respond, interact or even customize certain stories (interactivity), and think about ways to connect the story to other stories, archives, resources and so forth through hyperlinks (hypertextuality). This is the 'ideal-typical' form of online journalism, as professed by an increasing number of professionals and academics worldwide (in the US see, for example, Pavlik, 2001; in Germany see Friedrichsen et al., 1999: 139-43; Neuberger, 2000; in the Netherlands see Jager and Van Twisk, 2001; in Australia see Quinn, 1998). In so doing, scholars and professionals alike use the discourse of the internet's unique characteristics as a way in which to define online journalism as something different to other journalisms - as a 'fourth' kind of journalism, next to print, radio and television. Media professionals sometimes even claim 
different status, saying that online journalists are definitely 'a breed apart' (Meek, 2000). For example, scholars such as Lynn Zoch (of the University of South Carolina) argue that the media practitioners of tomorrow are (or should be) considerably different from the ones working today because of the internet:

By now it should be apparent that tomorrow's journalist will be a much different person - expected to make multiple-media news judgments, trained to make use of all news-gathering technology, flexible enough to work in news-gathering teams. (Zoch, 2001)

A new 'breed' of online news people, who produce content primarily for the WWW, can be seen as working under one or more of the four mentioned kinds of online journalism. These journalisms can be located on a continuum ranging from purely editorial content to public connectivitybased websites (see Figure 1).

The content-connectivity domain intersects with (vertical axis) the participatory communication domain. A brief note has to be made regarding the notion of 'content', as - in web designer terms - everything is online content, including banner ads, chatrooms, research papers and so forth. Editorial content is defined here as texts (including written and spoken word, moving and still images), produced and/or edited by journalists.

Public connectivity in this particular context is what Odlyzko (2001: 6) calls 'standard point-to-point' communication, where the notion of 'public' refers to communication without a formal barrier of entry (such as an editing or moderating process). For example, in specific terms of newsmedia production online, connectivity and public communication have been operationalized in terms of 'dialogical journalism': a journalism intended to promote public debate and to include local residents in the production of news stories (Heinonen et al., 2000; Martikainen, 2000). The horizontal axis reflects the primary goal of a kind of media organization or newsroom to either convey stories to people 'out there', to work as a facilitator of people telling each other stories. In other words: the content-connectivity axis represents the full spectrum of news sites between, for example, CNN Online on the one end, and Slashdot on the other. The vertical axis represents the level of participatory communication offered through a news site. Arguing from open to closed, a site can be considered to be 'open' when it allows users to share comments, posts, upload files (i.e. content) without moderating or filtering intervention. ${ }^{4}$ On the other end of the spectrum, 'closed' participatory communication can be defined as a site where users may participate, but their communicative acts are subject to strict editorial moderation and control.

It is important to note that not every type of online journalism can be completely demarcated by applying this model. The domains and axes serve 
as operational constructs to make distinctions between (elements of) journalisms online. Using this model, a news site (or parts thereof) can be defined as more or less constitutive of a certain type of online journalism not as exclusively 'fitting' to a specific type. In theory, this would move us away from establishing dualistic differences towards defining complex distinctions (Weber, 2000: 459-64). ${ }^{5}$ Of course, the model assumes that in fact 'opposite ends' do exist between moderated-unmoderated and contentconnectivity types of sites. It is important to understand that no single type of (online) journalism exclusively fits on one end of a continuum; any given type of journalism will involve characteristics or elements of several domains in this model. ${ }^{6}$

I will now shortly describe the four types of online journalism, as these can be seen as the most commonly operating distinctive journalisms on the web. It is important to note that when adding public connectivity elements to a news site operating in closed participatory communication with its publics, the site as a whole moves to the right in the model. Equally, when such a site relinquishes control over communicative interventions by (members of) the audience, it moves downwards in the model. In other words: adding (or subtracting) certain elements of either the contentconnectivity continuum or the open-closed participatory communication continuum has consequences for the typology of the news site as a whole.

\section{Mainstream news sites}

The most widespread form of newsmedia production online is the mainstream news site, generally offering a selection of editorial content and a minimal, generally filtered or moderated form of participatory communication (Schultz, 1999; Jankowski and Van Selm, 2000; Kenney et al., 2000). This type of content is distinctive in that it can be characterized as originated (produced originally for the Web) or aggregated (shoveled from a linked parent medium, 'framed' or 'deep-linked' from an external source not in the least done by so-called artificial market actors such as searchbots and spiders [software that automatically enables internet searches]; see Gatarski, 2001). Examples of the 'originator' type of mainstream news sites are the much-visited sites of CNN, BBC and MSNBC. Most online newspapers can be located in this category, as well as several 'Net-native' news sources - which are generally outside of the mainstream media. Correspondingly, academic research tends to ignore these, such as for example the much-acclaimed site of Alternet (part of an US-based nonprofit organization, the Independent Media Institute). The course materials, handbooks and curriculum planning of journalism schools and university departments can be considered to be largely based on this type on online journalism, combining technological skills (working with certain software, learning XML or HTML, for example) with specific news writing skills for 
the web (Nielsen and Morkes, 1997; McGuire et al., 2000). This type of news site does not differ much from print or broadcasting journalism in its approach to journalistic storytelling, news values, and relationships with audiences. Mainstream news sites tend to be operated by relatively closed networks of media owners and companies such as AOL/Time Warner in the US, or Kirchmedia, Vivendi and Sanoma in Europe (Pryor, 2002).

\section{Index and category sites}

A second type of online journalism is not so much located within the mainstream media organizations, as it is often attributed to certain search engines (such as Yahoo), marketing research firms (such as Moreover) or agencies (Newsindex), and sometimes even enterprising individuals (Paperboy). Here, online journalists offer (deep-) links to existing news sites elsewhere on the world wide web. Those hyperlinks are sometimes categorized and even annotated by editorial teams, thus generally featuring more or less contextualized (or contextually presented), aggregated content (see Paul, 1995). Professional debates regarding 'Netiquette' and web culture tend to question the ethics of these aggregation practices, as one should consider the admittedly thin line between offering a link to a site elsewhere, and simply copying someone else's content onto your own site (see also Deuze and Yeshua, 2001). These index and category sites generally do not offer much 'original' editorial content (cf. content produced exclusively or specifically for web publication), but do at times offer areas for chat or exchanging news, tips and links by the general public - for example by maintaining some kind of bulletin board system (BBS). A well-known example thereof is the option most search engines offer to 'add a site', which will then be subjected to editorial scrutiny. As a side note, one could argue that sites offering some editorial content and furthermore providing annotated links to content elsewhere on the web (similar to so-called 'portal' sites), such as the Australian Arts and Letters Daily, Bosnian Mario Profaca's Cyberspace Station or the infamous US-based Drudge Report by Matt Drudge, fall into this category. What is sometimes labelled as 'new' online journalism is the phenomenon of the weblog or 'blog', an often highly personal online periodical diary by an individual, not in the least by a journalist, telling stories about experiences online and offering readers links with comments to content found while surfing the web (Lasica, 2001; Blood, 2002; Perseus, 2002). These types of individual journalism (aka 'usergenerated content sites') can be located somewhere between index and comment sites, as they tend to offer limited participatory communication (being usually just one person speaking his or her mind about certain issues and offering links), but present plenty of content - and comment on content. $^{7}$ 


\section{Meta- and comment sites}

This third category of news sites contains sites about newsmedia and media issues in general; sometimes intended as media watchdogs (for US examples: Mediachannel, Freedomforum, Poynter's Medianews, E\&P's E-Media Tidbits; see Pavlik and Clayton Powell III, 2001), sometimes intended as an extended index and category site (European Journalism Centre's Medianews, Europemedia to name two European examples). Many sites worldwide serve as a meta- and comment type of online journalism in terms of media criticism or 'alternative' media voices; examples of which are Mediekritik.nu in Sweden, Extra! in the Netherlands, dotJournalism in the UK and OnlineJournalismus in Germany. ${ }^{8}$ Editorial content is often produced by a variety of journalists and basically discusses content found elsewhere on the internet. Such content is discussed in terms of the underlying media production processes. This 'journalism about journalism' - meta-media or meta-journalism - particularly flourishes online (as well as offline; see, for example, Boylan, 2000). In this respect the internet has contributed to further professionalization of journalism overall, as the ability and willingness to publicly reflect on itself and being openly self-critical is generally seen as one of the defining characteristics of a profession (Beam, 1990). Online metamedia such as meta- and comment sites can contribute to reinvigorating the function of journalism in 'carrying on and amplifying the conversation of people themselves' (James Carey, in Kovach and Rosenstiel, 2001: 18). An important factor for coining and including this category is the widespread emergence of so-called 'alternative' news sites. Alternative news sites tend to define themselves in terms of what they consider the mainstream (corporate, commercial) news organizations not to be. Such sites - notably the Guerilla News Network and the Independent Media Centers in various places across the globe - offer not only their own news online, but tend to critically comment upon the news offered by existing media networks, guiding users to places outside of the mainstream news offerings on the web. The Alternative Press Center, for example, maintains an extensive database of 'alternative voices' on the internet. Many of these sites exist as online journalisms in that they collect, annotate and comment upon sources of news all over the web, focusing explicitly on issues and angles that they feel the 'mainstream' journalists have not covered (well or sufficiently). As most of these sites also tend to allow individuals to upload and contribute their own stories in an open publishing environment, they can be seen to act as more or less 'participatory' metasites.

\section{Share and discussion sites}

As noted earlier, a critical distinction made in Figure 1 is the one between (a focus on) content and connectivity. Odlyzko (2001) in particular argues that the reason for the success of new media technologies such as the 
internet and the world wide web is that they facilitate the need for people to connect with other people worldwide, unhindered, in real time (see also Rushkoff, 1997). In other words: the internet is 'just' a communications infrastructure (Rushkoff, 2000). Online journalism utilizes this potential of the internet in that it facilitates platforms for the exchange of ideas, stories and so forth, often centred around a specific theme such as worldwide antiglobalization activism (the aforementioned Independent Media Centers, generally known as Indymedia) or computer news (Slashdot, featuring a tagline reading: 'News for Nerds, Stuff that Matters'). Several sites have opted to commercially exploit this public demand for connectivity, by organizing more or less edited platforms for discussion of content elsewhere on the Net (Plastic, kuroshin or 'corrosion'). ${ }^{9}$ This type of online journalism has also been described as 'group weblogs', offering personal accounts of individuals about their experiences on the internet (Lasica, 2001).

All four types of news sites can be considered to belong to a professional domain of journalism, as the function of (most of) these sites is still the same as the main purpose of journalism according to its dominant liberalprogressive definition in elective democracies worldwide: to provide citizens ${ }^{10}$ with the information that they need to be free and self-governing (Kovach and Rosenstiel, 2001: 17; see also Weaver, 1998). For online journalism, one could add the purpose of offering 'Netizens' platforms and tools to exchange the views and information needed in order to realize freedom and self-government.

\section{CHARACTERISTICS}

The four identified types of online journalism all to some extent utilize key characteristics (cf. web publishing paradigms) of the networked computer environment in which they operate: hypertextuality, multimediality and interactivity (Newhagen and Rafaeli, 1996; Bardoel and Deuze, 2001). Each of these three paradigms has its own logic, which I will try to exemplify by looking at the online news situation described earlier. ${ }^{11}$ Crucial in applying the suggested typology of online journalisms and the impact that this may have on news strategy and media theory regarding the internet is the understanding that using a certain type of interactivity, hypertextuality and/ or multimediality has consequences for the entire media production process, for the management of a news organization and thus for the journalistic culture (re-) produced. The four types of online journalism connect to the application of a series of distinct online features, which mutually reinforce each other's position and editorial focus.

\section{Hypertextuality}

The problem with hypertext, as one of its founding fathers, Ted Nelson, writes, is that it creates 'a delivery system for separate closed units - a 
system which allows only embedded links pointing outward' (Nelson, 1999). What one has to realise is that texts, interconnected through links hyperlinks - can refer internally (to other texts within the text's domain, 'onsite') or externally (to texts located elsewhere on the internet, 'offsite'). These are two quite different types of hypertextuality, as offsite linking opens up new content, and on-site linking in fact could lead to a downward spiral of content. If a site only refers to documents to be found within that particular site, it actually tells the end-user that the 'worldwide' web does not exist, that only the local documents on that site can, and should be, interconnected. Whether or not this is a good or bad thing is beyond the scope of this article, but I should like to acknowledge Nelson's claim that the whole purpose of hypertext in fact is to open up and make available all kinds of documents (content) as much as possible. More or less exclusive on-site linking does not seem to be particularly instrumental in this respect.

If one examines how today's news sites apply the concepts of internal and external linking, the conclusion has to be that few sites actually offer extensive offsite hyperlinks (Jankowski and Van Selm, 2000). But linking and integrating layers of external content - managing and opening up content is problematic, not least because of ownership and copyright infringements, as the international discussion on 'deep-linking' (bypassing a site's homepage with a hyperlink to directly access a certain page or fragment of information available online) shows - particularly in terms of online ethics. ${ }^{12}$

\section{Multimediality}

Web designer Tim Guay wrote as early as 1995 about the inherent pitfalls of applying multimedia content to websites:

[I]f multimedia is used with no thought as to the reasons why it is being used, or it has poor lay-out or content it can result in a pointless aesthetic fiasco that needlessly hogs bandwidth. (1995: 5)

Accepting for a moment that bandwidth and copyrights are two structural factors which have an impact upon the development of innovative multimedia content, one can observe the problems that media companies have in order to integrate their traditional newsroom with the web editorial team, let alone reaching out and integrating content (or even establishing 'virtual' newsrooms) with other content providers (Crosbie, 2001). This can be understood if one distinguishes multimediality in news sites as a result of convergence of media modalities, or as a divergent paradigm..$^{13}$ Following the first paradigm, multimedia can be seen as the combination of information offered in different formats, produced in different sections of one or more media organizations. In the second paradigm all parts of the site are developed from a multimedial starting point, offering the end-user several ways into, and through, the site's contents. Even though very few 
websites in fact employ multimedia, most of the news sites that do use it, do so from a modestly convergent perspective (the BBC is a good example). Those who are clearly divergent are often products outside of the mainstream (such as Rockstargames.com), with notable exceptions such as the Tampa Bay Tribune's multimedia facility (TBO.com), which moved during 2000 to 2002 from a convergent to a more or less divergent paradigm in terms of the organization of the newsroom.

One could express doubts at the industry's drive to media convergence, following the argument that it could be simply another way of producing more content with less news people (Devyatkin, 2001). Another point of concern is whether or not producers of news indeed embrace the new technology for its potentially 'democratizing' features - such as using small, handheld devices to record not only what existing cameras and microphones would, but also to sample voices from different peoples outside the mainstream. This reflects the 'dual' nature of multimedia development: on the one hand, one has to consider sheer technological advancements and new storytelling possibilities, on the other, our understanding of the impact of such technologies on the culture of (online) journalism must be critically articulated. In other words, introducing multimedia in a newsmedia organization perhaps has less to do with developing all kinds of (new) resources and skills, but more about understanding and developing a different, diverging journalistic news culture (Carr, 2002).

\section{Interactivity}

Interactivity is a term or concept which is not, in itself, exclusively part of the internet discourse, as earlier media and types of mediated communication have claimed to be more or less interactive - within journalism one can think of talk radio, for example (Deuze, 1999: 377). It has also been part of academic discourse, where authors have sought to define the concept either in terms of participatory communication and control over content between users, or as an indicator of a more or less elaborate feedback mechanism of two-way or multiple way communication (Steuer, 1992; King, 1998). Yet the kinds of interactive options that the internet offers for journalism can be distinguished from a 'pre-web' context in terms of what Pavlik (2001: 125-48) has described as a different mode of addressing the news audience: as active instead of passive media consumers. In fact one could argue, that 'consumers' is not the right term here - one may talk about 'high end-users' (Pryor, 2002). The literature on online journalism indeed refers to interactivity as the characteristic of the internet which facilitates association, enabling people not only to receive information - remember the 'passive' audience - but also to disseminate it (Kopper et al., 2000: 509). In buzzword-jargon one may speak of online users as 'prosumers' of news. ${ }^{14}$ Therefore, interactivity can be seen as a broadly 
defined concept with many implications for mediated communication of all kinds, and for journalism in particular (see Heeter, 1989; Loosen and Weischenberg, 2000). Massey and Levy (1999: 526) argue that interactivity applies particularly to online media production in four ways: complexity of choice available, responsiveness to the user, facilitation of interpersonal communication and ease of adding information. These four 'dimensions' are translated in the context of this article as distinct elements of the design of web (news) sites, as I am interested in the ways in which online journalisms apply the distinct features of the web to their 'storytelling' capacities. Interactive options on websites can be subdivided into three types:

(1) navigational interactivity: the user is allowed to navigate in a more or less structured way through the site's content (through 'Next Page' and 'Back to Top' buttons or scrolling menu bars, for example);

(2) functional interactivity: the user can participate to some extent in the production process of the site by interacting with other users or the producers of a particular page or site (through direct mailto: links, bulletin board systems (BBS), and moderated discussion lists, for example); and

(3) adaptive interactivity: every action of the user has consequences for the content of the site, as the site's programming adapts itself to the surfing behaviour of every individual user and 'remembers' users' preferences (allowing users to upload, annotate and discuss their own content, offering chatrooms and personal customization through smart web design).

Guay (1995) argues that the most sophisticated level of interactivity is adaptive, meaning that it allows the website to adapt itself (ideally in real time) to the behaviour of the visiting surfer. Online news reception research by Shyam Sundar (2000) reveals that the more interactive opportunities websites give to users, the more involved the users will feel about the website. Outing (2001) comments that this will work even when surfers do not really use all these interactive 'bells and whistles' themselves. This suggests a fourth, overall level of interactivity: a third-person interactivity of a site, as in: 'I do not want to - or feel the need to - participate in an online discussion or email the editors, but other people can, and its really cool that the site offers users that option. ${ }^{15}$ While observing interactive options in news sites, several scholars have noted that most sites do not develop interactivity beyond functional and navigational levels (Massey and Levy, 1999; Schultz, 1999; Jankowski and Van Selm, 2000; Kenney et al., 2000). Recent cross-national research by the EU-funded Mudia project shows that 'old school' or traditional journalism approaches - generally 
lacking in advanced interactive options - indeed still dominate the web across Europe (Quinn and Trench, 2002; White, 2002).

The next step in our analysis should demonstrate to what extent these features of the internet could be seen as located within the four journalisms online. This should be interpreted as the ways in which the journalisms have developed each of these characteristics in particular - not necessarily exclusively. For corporate news sites, the aforementioned Editor and Publisher Interactive and the Kidon Medialink databases have been very useful as international indexes. For alternative and net-native sites operating outside of the mainstream, the links sections of AlterNet and Indymedia serve their purpose.

Mainstream news sites overall seem to operate on the level of internal hypertextuality (offering few links pointing outwards) with mainly navigational interactivity (most news sites do not even offer their reporters' email addresses, let alone mailto: links), and only on rare occasions do they offer convergent multimedia. Another analytical point also has to be made: when news sites in fact do offer all kinds of advanced multimedia or interactive options, it is rarely, or never, made clear why this is done.

On the other hand, index and category sites rely almost exclusively on external hypertextuality, as they gather, index and categorize editorial content found elsewhere on the world wide web. Their interactivity is also navigational, which might be explained (as in the case of mainstream news sites) by the fact that they concentrate on content rather than connectivity. These sites seldom apply multimedia, unless they specifically intend to index images (as, for example, specialized search engines offer JPEG- or MPEGsearch robots with editorial annotation).

Similarly, meta- and comment sites are not likely to offer multimedia content, and tend to rely on external links. As these sites are generally made by one or more media critics - or 'inspired' individuals in the case of weblogs - they tend to use functional interactivity (Lasica, 2001). One could argue that this could be seen as serving as some kind of accountability: allowing the surfer to submit feedback, tips or content directly to the people responsible for the metasite. As these sites also serve as a kind of annotated index of journalisms 'out there', the hypertextuality on offer is predominantly external.

Generally, share and discussion sites are based exclusively on written word texts. ${ }^{16}$ The sites in this category concentrate on public connectivity, where the posts, threads and submissions of surfers form the basis of the site's content. This results in the employment of different levels of interactivity, including adaptive interactive options in particular (see, for example, the options for files sections, shared agendas and chat sessions offered by free mailing list agents such as Yahoogroups, Topica, Listbot). These sites can be typified by the fact that people use the site's 'brand' through which to 
communicate (with each other), instead of using the brand to communicate with - as is the case with the other three types of sites (see, for example, Slashdot, Plastic, Backwash, but also Indymedia, Drop, and Kuro5hin). Hyperlinks to sites elsewhere are often used as starting points for discussion, whereas an ongoing discussion may lead on to links to additional pages within the online community.

In the context of this article, the assumption is that ideal-typical online journalism cannot be simply the sum of the added values of its distinct types. In order for a news site to become interactive in a participatory way, or a discussion site to begin offering quality multimedia content, the particular newsroom has to undergo quite a few changes and face some tough choices about values, goals and standards - not least having to deal with the problematic commercial aspects of electronic publishing routines and the impact that such choices may have on management and newsroom organization. Therefore, I should like to conclude this overview of online journalisms, characteristics and added values by looking at what the consequences of such 'new' types of journalism online may be, and their added value for the existing dominant news culture in contemporary journalism (operating in the context of Western elective democracies).

\section{CONSEQUENCES}

When news sites opt to add or increase (external) hyperlinks, (functional/ adaptive) interactivity and (convergent/divergent) multimedia, they also opt for changes beyond the addition of some underlined text, an extra page with a feedback form or a link to a streaming video fragment. Such changes also have to do with editorial organization patterns, and challenges to established journalistic ways, norms and values of storytelling. Living up to the characteristics and potential added value of journalisms online particularly challenges perceptions of the roles and functions of journalism as a whole. The suggested added values and characteristics of online journalisms cannot simply be incorporated one-by-one without fundamentally changing the 'nature of the beast' - the beast being that particular newsroom culture and the professionals involved. Different and overlapping types of online journalism may very well change what one perceives as 'real' journalism, as their distinctive features have implications for the way in which media production processes are focused, how news organizations are managed, and how a journalistic culture operates (in relationship with audiences and technologies).

Although an expanding body of scholarly work addresses technological and cultural issues regarding new media, the internet and online journalism, few authors combine such insights and research into a broader framework of thinking about journalism and media production processes as a whole. Some of the few theoretical 'futurological' authors who have philosophized in 
particular about the impact of changes and challenges on journalism because of the internet on the future development of 'old' and 'new' forms of journalism are, for example, in the Netherlands, Bardoel (1996; see also Bardoel and Deuze, 2001); in the US, Singer (1998) and Pavlik (1999); in Sweden, Dahlgren (1996); in Finland, Heinonen (1999); and in Germany, Neuberger (2000). ${ }^{17}$ The work of these authors, coming from extremely 'wired' societies, forms the basis of the consideration of online journalisms' consequences offered here. In particular, Bardoel predicts that, mainly because of audience fragmentation, increased dependency on new technologies, empowered users through interactivity, and disintermediation developments, two types of journalism will evolve: orientating and instrumental journalism (1996: 296- 7). In his view, orientating journalism provides a general public with general orientation (background, commentary, explanation). On the other hand, instrumental journalism offers functional, specialized information to interested audiences or customers. Correspondingly, Singer (1998) and Pavlik (1999) take up the challenge of investigating new ways of framing more or less traditional research questions to be posed to communicator and gatekeeper studies. These and most other mentioned approaches suffer from the same bias, as authors tend to implicitly assume that the future of journalism is still primarily determined by (a monopoly on) storytelling by journalists for citizens. On the other hand, the overview of the characteristics and typology of online journalism suggests much of journalisms' potential can (or even should) be found in reversing this paradigm, where journalists offer citizens annotated archives for self-searching purposes, provide people platforms and modes for participatory, connective storytelling - in various ways interactive, hyperlinked, multimedial. One has to consider the different futures of journalism as existing next to - in a more or less symbiotic relationship with - content-based notions of news work. Figure 2 addresses this potential, looking at the consequences for the profession of journalism as a whole, while on the previous model of more or less distinctive (yet coexisting) online journalisms in particular.

If one considers the fact that the suggested potential of 'new' journalisms particularly resides in the domain of connectivity, one must consider what this could mean for the roles and functions of journalism. Therefore I should like to introduce the concepts of monitorial journalism (following Schudson, 1999a) and dialogical journalism (in terms of Martikainen, 2000). As the mainstream newsmedia tend to operate in a relatively closed journalistic culture - where structural coupling with audiences and other stakeholders in the news can be seen as moderated and filtered to suit the needs of reporters and editors (Weischenberg and Scholl, 1998) - the general content that they provide tends to be oriented towards a perhaps well-defined, but also largely 'constructed' audience (Ettema and Whitney, 


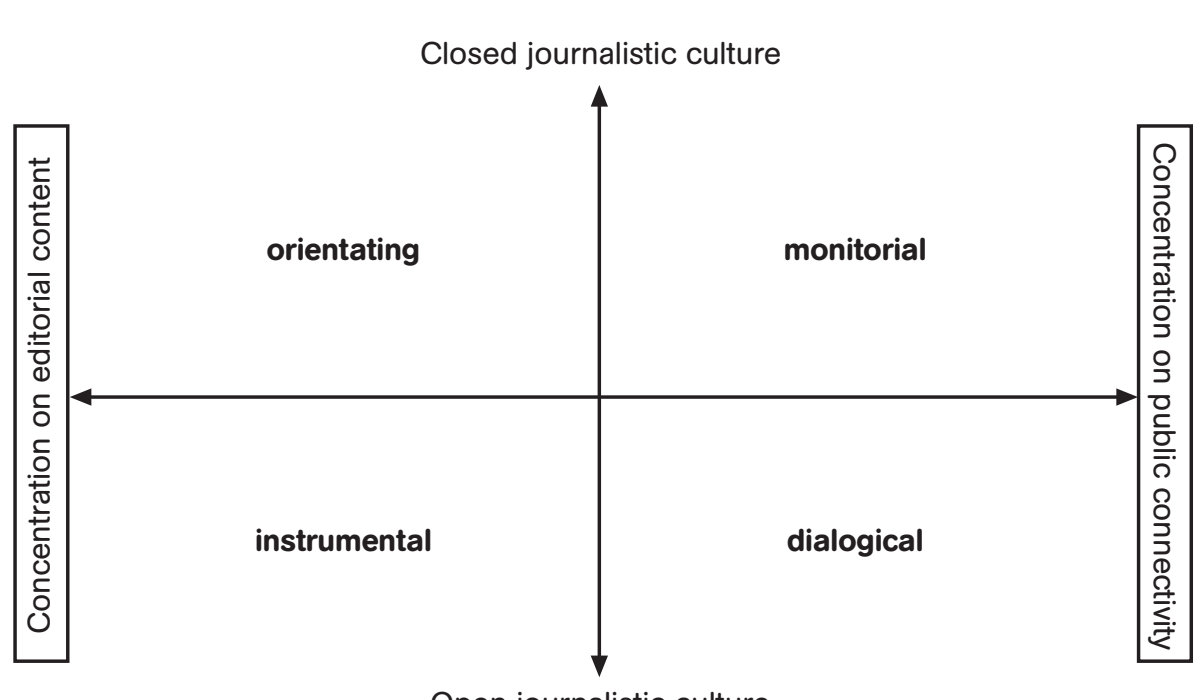

Open journalistic culture

- Figure 2 Types of journalism between content and connectivity

1994; Alasuutari, 1999). The role of the audience is recognized, but also taken for granted, or even just imagined (Ang, 1991). As instrumental to the specific wants and needs of an audience, journalism caters more specifically to people as news consumers - and therefore requires a more open (as in interactive, responsive, accountable) journalistic culture. An example of such open interaction between journalists and their publics online is open source journalism: draft versions of news stories are pre-published online and rewritten with the input of site users (Preecs, 2000; Deuze, 2001). This increased emphasis on 'knowing' and 'using' the audience as a journalist must not be exaggerated. For example, critics of the public journalism movement in the US have laid bare a specific problem surrounding today's journalists; they do not know who their publics are, nor what these people could expect of them and how this would have an impact on their work (Schudson, 1999b). Tapping into the news agenda of a wide variety of publics can be considered to be one way of doing, or offering instrumental journalism. In its emphasis on signalling and contributing to the resolution of problems in contemporary society, public journalism comes closest to this type of journalism. However, as Schudson (1999b) and Woodstock (2000) convincingly demonstrate, the tone of voice and position of journalism as dominant provider of content and narratives about 'reality' is not structurally challenged in public journalism.

A first step toward shifting journalists' focus from content to connectivity could lie in the concept of monitorial journalism. Journalism still professionally feels the pulse of society, and it does not function as sole provider of content. One could imagine that a website is a specific, useful 
platform for allowing citizens to voice their opinions and questions regarding the issues about which they care. If this connective emphasis is still located within a closed journalistic culture, one could imagine journalism to become like a so-called Frequently Asked Questions (FAQ) site, where online editors and reporters answer the demands of their publics by posting stories, backgrounds and annotated links in a FAQ-capacity. A more radical and democratic way of locating connectivity and an open culture in journalism would be dialogical journalism, where the contents of a news medium - for example, a (part of a) website - are fully maintained by journalists interacting with citizens. In other words, a strict division no longer necessarily remains between producers and consumers of news content, as all become 'prosumers'. An experiment in Finland shows that this can work for the benefit of all involved in a well-defined and wired locality (Martikainen, 2000). As such, this type of journalism may indeed come close to James Carey's ideal of professionally amplifying the conversation of society and its citizens.

The typology of online journalisms as presented in this article closely connects with making the distinction between different types of journalism as a whole: orientating, instrumental, monitorial and dialogical journalism. By drawing the models on more or less similar conceptual grounds (applying distinctions between open and closed, and between content and connectivity), various interactions between the different typologies become visible. This suggests that the unique differences between new kinds of journalism developing on the internet and journalisms existing within other media modalities reveal much wider developments, and thus consequences for contemporary journalism and media production as a whole. For example, Mainstream news sites tend to translate the traditional way of doing things to the web, repurposing not only their content, but also their journalistic culture (including relationships with publics). This partly explains why most newsmedia organizations opt for producing fairly straightforward news sites when going online. Index and category sites potentially go a step further, as these sites offer linked (and sometimes annotated) content related to specific topics or issues, sometimes voiced through specific (virtual/ geographical/temporal) communities. Therefore, this second type of online journalism can be seen as instrumental. Meta and comment sites can go either way: instrumental and/or orientating, in terms of a news medium commenting on the way in which other media work on issues of specific or general interest; or monitorial, when the site's publishing model functions on the basis of comments, questions, hints and tips offered by individual site visitors. Share and discussion sites can be seen as dialogical by definition, as their main function is to be a platform for (real-time) communal uploading, filtering, exchanging and discussion of content. 
The benefit of connecting the typology of journalisms found online however admittedly simplistic - to a typology of different kinds of journalism on the continuum between content and connectivity is that it provides a more profound understanding of the (potential) shifts and changes occurring within professional journalism as a whole. A mainstream news site embracing connectivity must consider the impact that this will have on its established culture of doing things, its monopoly on content, its understanding of what is 'public', its roles in community. This is not to be underestimated, and in my opinion explains the failed or uninspiring nature of attempted interactivity by this kind of news organization (see, for example, Schultz, 1999). A share and discussion site opting for editorial content also challenges its dominant mode of operation - particularly its open and interactive relationship with communities online. For example, research among Indymedia activists indeed reveals their ongoing discussions about whether or not to assume a more traditional role as gatekeeping journalists on their websites, because of the uncontrollable nature of uploaded content - sometimes resulting in 'hate speech' toward certain groups in (cyber-) society (Platon and Deuze, 2003).

To reiterate: connecting changes in journalism because of new technologies such as the internet to changing definitions of different types of (possible) contemporary journalism shows us that a news medium considering or implementing new strategies has to enable its organization to reflexively address the existing journalistic culture and rethink its location on the continuum between content and connectivity. If not, it cannot be expected to fully grasp the consequences of these changes - and thus it cannot be expected to succeed. When surfing the net and connecting to the wide variety of news sites on offer, one has to note the fact that most of these sites incorporate one or more of the typologies and characteristics of online journalism as mentioned here. Whether or not these newsmedia have considered the implications thereof in terms of the different types and functions of journalism, can be considered to contribute to the success or failure of these many-sided websites.

\section{Conclusion}

It seems clear that the implications discussed in this article are dependent on how the discussion between traditional and new ways of storytelling is resolved within the newsroom involved. This is an aspect that is underestimated by online journalists and researchers, for example, who study the interactiveness of news sites. They talk about the importance of being interactive without accepting the fact that ongoing levels of interactivity undermine the 'we write, you read' dogma of modern journalism, and of having an impact upon certain core values and ideals along the way (see, for example, Fulton, 1996; Pavlik, 2001). It is the same for annotation to 
external hypertextuality, as for increasing a news site's adaptive capacity. A mainstream news site without any kind of interactive option is not an example of 'bad' online journalism; it may be an excellent service to its constituency demanding brief, concise and updated information throughout day and night.

This article has aimed to summarize the kinds of online journalism, their characteristics and added value to other journalisms, and tried to evaluate the impact on, and challenges of, new developments in online newsmedia production. The summary is by no means all-inclusive, and exceptions to the two models suggested in this article are no doubt to be found all over the web. What I would like to suggest is that any assessment of what is good or bad about online journalism should begin with a clear and perhaps oversimplified description of the concepts that one is addressing. I consider this article an attempt to provide such a description - hopefully leading to a sharpening of our research problems and questions, a redefinition of newsmedia strategies and a starting point for evaluation before implementing change. Different kinds of journalism online amplifies and affects different kinds of journalism offline. Journalism as a whole is changing, and the models and argument offered in this paper should be seen as an attempt to better understand these developments.

\section{Appendix: Links}

$\begin{array}{ll}\text { CNN } & \text { www.cnn.com } \\ \text { BBC } & \text { news.bbc.co.uk } \\ \text { MSNBC } & \text { www.msnbc.com } \\ \text { AlterNet } & \text { www.alternet.org } \\ \text { Altavista } & \text { www.altavista.com } \\ \text { Yahoo! } & \text { www.yahoo.com } \\ \text { Moreover } & \text { www.moreover.com } \\ \text { Newsindex } & \text { www.newsindex.com } \\ \text { Paperboy } & \text { www.thepaperboy.com } \\ \text { Arts \& Letters Daily } & \text { www.aldaily.com } \\ \text { Mario Profaca's newssite } & \text { mprofaca.cro.net } \\ \text { Drudge Report } & \text { www.drudgereport.com } \\ \text { Mediachannel } & \text { www.mediachannel.org } \\ \text { Freedomforum } & \text { www.freedomforum.org } \\ \text { Poynter's Medianews } & \text { www.poynter.org/medianews } \\ \text { E-Media Tidbits } & \text { www.content-exchange.com/cx/weblog/weblog.htm } \\ \text { EJC Medianews } & \text { www.ejc.nl/medianews.hmx } \\ \text { Europemedia } & \text { www.europemedia.net } \\ \text { Guerilla News Network } & \text { www.gnn.tv } \\ \text { Alternative Press Center } & \text { www.altpress.org } \\ \text { Indymedia } & \text { www.indymedia.org } \\ \text { Slashdot } & \text { ww.slashdot.org } \\ \text { Plastic } & \text { www.plastic.com } \\ \text { Mediekritik } & \text { www.mediekritik.nu } \\ & \end{array}$




\author{
Mudia \\ Extra! \\ Dotjournalism \\ Online Journalisms \\ Nerve \\ Feed \\ Rockstargames \\ Backwash \\ Drop \\ Kuro5hin
}

\author{
www.mudia.org \\ www.extra-media.nl \\ www.journalism.co.uk \\ www.onlinejournalismus.de \\ www.nerve.com \\ www.feedmag.com \\ www.rockstargames.com \\ www.backwash.com \\ www.drop.org \\ www.kuro5hin.org
}

\section{Acknowledgements}

The author wishes to thank Tamara Witschge (University of Amsterdam), Froukje Santing and the Internet Section of the Dutch Association for Journalists (NVJ), Gustavo Cardoso (ISCTE Lisbon), Nick Jankowski (University of Nijmegen), Michelle Nicolosi and Larry Pryor (Online Journalism Review), Alan Knight (Ejournalist) and Edward Valauskas (First Monday) for comments on earlier drafts, and the opportunity to present and discuss (previous parts/versions of) this article.

\section{Notes}

1 All the sites mentioned in this article are listed with their addresses (URLs) on the world wide web in the appendix, in the order as they appeared in the body text. Admittedly, most of these sites are in English and are therefore not representative of the multitude of voices online - as English native speakers make up about 36 percent of all users on the world wide web in September 2002 (source: Global Reach Statistics, see http://www.glreach.com/globstats/).

2 See, amongst other, in the Netherlands work by Deuze, in the US, publications by Singer, Neuberger in Germany, and Heinonen for Finland.

3 By focusing on post 1991-literature I omit a vast body of work on electronic media and 'new' media in general as these relate to information, communication and media (see, for example, the first issue of New Media \& Society in 1999 for a thorough discussion on what's new in 'new' media). Although it would be relevant to include that literature here, it would also change the focus of this particular article - which is to identify and analyse what is happening 'now' in online newsmedia and how this relates to our understanding of online journalism in general. I want to argue that it is important to historicize the views in this article by pointing at the opposition in the literature between 'evolutionists' - those who see emerging patterns of communication on the web on a continuum of the way in which people did things before - and 'revolutionists' - as those who think all is, or will be, different now (because of the web). The inherent normative perspective: things progress and new media contribute to making things 'better'. Carey (1989 [1975]: 34) has warned against reducing advances in communications technology to benefit politics and economics, instead of opportunities for real people. My point here is that the fastpaced and widespread proliferation of the web enables us to look at journalism anew, without dismissing all that came before (see also Allen and Miller, 2000). This will neither make things better or worse, nor will it just be continuity or discontinuity; it will hopefully be inspiring to rethink and repostulate by taking that which is distinct about this decade of web developments and use it as a looking glass for that what is distinguishable on the web: online journalisms. 
4 Allen and Miller (2000: 57) give the example of Usenet newsgroups as typical forms of unmoderated 'public spheres', while still operating under certain conditions of access. Agre (1997) argues more or less correspondingly that scholars and journalists alike tend to overlook a wealth of unmoderated yet flourishing online communities, because these tend to be areas of the net to which one cannot gain easy access.

5 Philosophically speaking, one could argue that this distinction approach connects to the fierce attacks of authors such as Bhabha, Jokisch and Rorty against the 'binary oppositons' or 'binary paradigms' used in social sciences to dualistically distinguish and define phenomena under investigation. Instead, such authors would argue in favour of conceptual hybridity, distinction and (pragmatic) complexity (Rorty, 1982; Bhabha, 1995; Jokisch, 1996; Weber, 2000).

6 In this respect it may be helpful to consider Philip Agre's (1997) work on genres for new media, where he distinguishes different genres in designing new forms of communicative interaction. His genres are similar to my use of 'types' of online journalism, particularly with respect to the broad definition of genres/types, the implications of each genre/type for relationships between producer(s) and consumer(s) of information, the fact that each type/genre implies a stream of documents and web pages (not just one), and the tendency of this crude typology to change constantly. To this, one could add that each type of news site relates to different types of news content: sports, economics, 'hard' and 'soft' news, and so forth. Empirical evidence may shed light on which type of news content can be located within which type/genre of news site/online journalism. Most content analyses have focused on 'hard' (political-economical) news thus far (see, for example, Jankowski and Van Selm, 2000; Kopper et al., 2000).

7 See, in particular, one of the first well-known weblogs by free speech activist and open source guru Richard Stallman at http://www.stallman.org. Weblogs operate with software applications like 'Blogger', which is the largest weblog publishing service; it automatically formats entries, organizes them, and transfers them into a user-defined template that is live on a site, which then can be used by (interconnected) communities, individuals and/or news sites. Editor and Publisher column writer Steve Outing called for journalists to all start their own weblogs on 26 June 2002 (see http://www.editorandpublisher.com). Several mainstream newssites such as Salon.com have started editors' weblogs, and MSNBC.com also started a weblog portal (see http://www.msnbc.com/news/809307.asp?cp1 =1) during 2002.

8 I apologise for appearing eurocentric or etnocentric in my link selection; primarily this has to do with language impediments, and does not mean that there are no excellent examples of different types and genres of news sites in all the different parts of the wired world; particular Eastern and Southern Europe (Czechoslovakia, Portugal), Southern Africa (South Africa) and South America (Brazil) have a reputation for producing many different and exciting online initiatives.

9 No commercial success story, though: Automatic Media, the company running sites such as Plastic and Feed, closed its doors on 11 June 2001 due to a lack of advertising revenue. Two editors of Plastic (with the tagline: 'Recycling The Web In Real Time') remain to keep the site running on a voluntary basis.

10 In our case, one could use instead of citizens the older buzzword: 'Netizens' (Hauben and Hauben, 1998; see the 1996 URL: http://www.columbia.edu/ rh120/).

11 See Dahlgren (1996: 63) for a discussion on online media logic, defined as the particular institutionally structured features of a medium, the ensemble of technical and organizational attributes which have an impact on what is represented in the medium and how it gets done. This notion can be used not only to discuss content 
and connectivity features on news sites - as is done in this article - but also to describe and explain the characteristics of online media professionals in terms of their competences and attributes (Deuze and Dimoudi, 2002).

12 See for example the 'Letters' section of Poynter's Medianews for the Belo case in the US (Spring 2002); in the Netherlands, a similar case involved publishing house PCM and website Kranten.com in summer 2000.

13 This discussion regrettably bypasses the problem of defining multimedia, as 'multimedia' can be considered to be several things at the same time, at once referring to integration of all kinds of information and/or technologies and/or forms of communication (Kennedy, 2002: 6). The pragmatic approach chosen here, is that it signifies what it predominantly means for news organizations: any and all combinations of editorial content in terms of written text, still and moving images, sounds, data and graphics.

14 The word 'prosumer' is generally ascribed to Toffler's book The Third Wave, where the futurologist writes about 'the willing seduction of the consumer into production' (1981 [1980]: 286). The common meaning of the term seems to be limited to marketing people, although the point made about involving consumers in the creative process of production is a vital one in the context of the argument presented here (see also Quinion, 1999).

15 The third-person effect refers to people's tendency to believe that the effects of the media will be stronger or more prevalent to others than themselves (see, in particular, Davison, 1983).

16 The site of Freespeech TV can be seen as a specific exception in this case, as it is based on broadcasting content unavailable through the established mainstream media infrastructure (cf. divergent multimedia). From interviews with media activists, it follows that they feel the mainstream media are increasingly underestimating the growth and potential of these 'individual television channels' on the web (Platon and Deuze, 2003).

17 This is, of course, not to say there are no other publications on these issues; recent overviews on (journal) publications on online journalism and journalists suggest that these topics feature in all major (English, Spanish, and German language) journals and books (see, for example, Deuze, 1998; Altmeppen et al., 2000; Kopper et al., 2000). Very rarely do such publications address journalism as a whole or online journalism in particular from a 'new' theoretical perspective - looking at website content analyses, user survey data or interviews with journalists from uses and gratifications or diffusion of innovations perspectives. The works cited here are an exception to this rule. Another problem of most scholarly work in the field of journalism studies is a loyalty to mainstream corporate media organizations, and in particular to newspapers. This article aims to contribute to bridging this gap in communication research, while acknowledging the innovative work that has been done in, for example, technology studies and cultural studies regarding web cultures and communities (see Gauntlett, 2000).

\section{References}

Agre, P.E. (1997) 'Designing Genres for New Media: Social, Economic, and Political Contexts', UCLA paper, available online, URL (consulted 4 July 2002): http:/

/dlis.gseis.ucla.edu/people/pagre/genre.html

Alasuutari, P. (ed.) (1999) Rethinking the Media Audience. London: Sage.

Allen, R. and N. Miller (2000) 'Panaceas and Promises of Democratic Participation:

Reactions to New Channels, from the Wireless to the World Wide Web', in S. Wyatt, 
F. Henwood, N. Miller and P. Senker (eds), Technology and In/Equality: Questioning the Information Society, pp. 46-60. London: Routledge.

Altmeppen, K., H. Bucher and M. Loeffelholz (eds) (2000) Online Journalismus:

Perspektiven fuer Wissenschaft und Praxis. Wiesbaden: Westdeutscher Verlag.

Ang, I. (1991) Desperately Seeking the Audience. London: Routledge.

Bardoel, J.L.H. (1996) 'Beyond Journalism: a Profession Between Information Society and Civil Society', European Journal of Communication 11(3): 283-302.

Bardoel, J. and M. Deuze (2001) 'Network Journalism: Converging Competences of Media Professionals and Professionalism', Australian Journalism Review 23(2): 91-103.

Beam, R.A. (1990) 'Journalism Professionalism as an Organizational-Level Concept', Journalism Monographs 121. Columbia, NY: Association for Education in Journalism and Mass Communication.

Bhabha, H. (1995) Location of Culture. London: Routledge.

Blood, R. (2002) The Weblog Handbook. Cambridge, MA: Perseus Publishing.

Boylan (2000) 'The Critics: a Thousand Voices Bloom', Columbia Journalism Review, March/April, URL (consulted November 2000): http://www.cjr.org/year/00/2/ voices.asp

Callahan, C. (1998) A Journalist's Guide to the Internet: the Net as a Reporting Tool. Boston, MA: Allyn and Bacon.

Carey, J.W. (1989[1975]) 'A Cultural Approach to Communication', in J.W. Carey, Communication as Culture, pp. 13-36. Boston, MA: Unwin Hyman.

Carlson, D.E. (2001) 'Online Timeline', URL (consulted March 2001): http://iml. jou.ufl.edu/carlson/professional/new_media/

Carr, F. (2002) 'The Truth About Convergence', Poynter 'Today's Centerpiece' 2 May, URL (consulted January 2003): http://www.poynter.org/content/content_ view.asp?id $=9677$

Cooper, T.W. (1998) 'New Technology Effects Inventory: Forty Leading Ethical Issues', Journal of Mass Media Ethics 13(2): 71-92.

Cottle, S. (1999) 'From BBC Newsroom to BBC Newscentre: on Changing Technology and Journalist Practices', Convergence 5(3): 22-43.

Crosbie, V. (2001) 'A New Economics for a New Medium: why Web Site Periodicals Cannot Profit', speech delivered at the NetMedia 2001 Conference, London, 5 July, available online, URL (consulted May 2002): http://www.digitaldeliverance .com/speeches/netmedia/netmedia.html

Dahlgren, P. (1996) 'Media Logic in Cyberspace: Repositioning Journalism and its Publics', Javnost/The Public 3(3): 59-72.

Davison, W.P. (1983) 'The Third-person Effect in Communication', Public Opinion Quarterly 47(1): 1-13.

De Wolk, R. (2001) Introduction to Online Journalism: Publishing News and Information. Boston, MA: Allyn and Bacon.

Deuze, M. (1998) 'The WebCommunicators: Issues in Research into Online Journalism and Journalists', First Monday 3(12), URL (consulted February 1999): http:/ /www.firstmonday.dk/issues/issue3_12/deuze/index.html

Deuze, M. (1999) 'Journalism and the Web: an Analysis of Skills and Standards in an Online Environment', Gazette 61(5): 373-90.

Deuze, M. (2001) 'Understanding the Impact of the Internet: on New Media Professionalism, Mindsets and Buzzwords', EJournalist 1(1), URL (consulted December 2001): http://www.ejournalism.au.com/ejournalist/deuze.pdf 
Deuze, M. (2002) 'National News Cultures: A Comparison of Dutch, German, British, Australian and U.S. Journalists', Journalism Quarterly 79(1): 134-49.

Deuze, M. and D. Yeshua (2001) 'Online Journalists Face New Ethical Dilemmas: Report from the Netherlands', Journal of Mass Media Ethics 16(4): 273-92.

Deuze, M. and C. Dimoudi (2002) 'Online Journalists in The Netherlands: Towards a Profile of a New Profession', Journalism 3(1): 103-18.

Devyatkin, D. (2001) 'Online Journalism: Digital Video Stars', Content Wire, 21 May, URL (consulted January 2003): http://www.content-wire.com/FreshPicks/Index .cfm? $\mathrm{ccs}=86 \& \mathrm{cs}=316 \&$ Highlight $=$ Devyatkin

Ettema, J.S. and D.C. Whitney (eds) (1994) Audiencemaking: How the Media Create the Audience. Thousand Oakes, CA: Sage.

Friedrichsen, M., R. Ehe, T. Janneck and M. Wysterski (1999) 'Journalismus im Netz: zur Veraenderung der Arbeits- bzw. Selektionsprozesse von Journalisten durch das the Internet', in W. Wirth and W. Schweiger (eds), Selektion im the Internet: Empirische Analysen zu einem Schluesselkonzept, pp. 125-45. Opladen: Westdeutscher Verlag.

Fulton, K. (1996) 'A Tour of our Uncertain Future', Columbia Journalism Review, URL (consulted December 1997): http://www.cjr.org/html/96-03-04-tour.html

Garrison, B. (2000) 'Diffusion of a New Technology: On-line Research in Newspaper Newsrooms', Convergence 6(1): 84-105.

Gatarski, R. (2001) 'Artificial Market Actors: Explorations of Automated Business Interactions', School of Business Research Reports 15. Stockholm: Stockholm University School of Business.

Gauntlett, D. (ed.) (2000) Web.studies: Rewiring Media Studies for the Digital Age. London: Arnold.

Guay, T. (1995) 'Web Publishing Paradigms', Information Technology Project Group paper, URL (consulted January 2003): http://www.smcc.qld.edu.au/infotech/ Paradigm/

Hall, J. (2001) Online Journalism: a Critical Primer. London: Pluto Press.

Hauben, M. and R. Hauben (1998) 'Netizens: on the History and Impact of Usenet and the Internet', First Monday 3(7), URL (consulted July 2002): http://www. firstmonday.dk/issues/issue3_7

Heeter, C. (1989) 'Implications of New Interactive Technologies for Conceptualizing Communication', in J.L. Salvaggio and J. Bryant (eds), Media Use in The Information Age, pp. 217-35. Hillsdale, NJ: Lawrence Erlbaum.

Heinonen, A. (1999) Journalism in the Age of the Net. Tampere: Acta Universitatis Tamperensis.

Heinonen, A., M. Makinen, S. Ridell, A. Martikainen, M. Halttu and E. Sirkukunen (2000) 'Locality in the Global Net: the Internet as a Space of Citizen Communication and Local Publicness', University of Tampere research report, URL (consulted May 2002): http://mansetori.uta.fi/report/default.htm

Hopscotch (2002) 'Premier barometre international sur les médias et les nouvelles technologies', Hopscotch report, URL (consulted May 2002): http://www. hopscotch-europe.com/fr/actualites/Fichiers/2_n_cp_04_04_2002Barometre.pdf

Jager, R. and P. Van Twisk (eds) (2001) Internetjournalistiek. Amsterdam: Boom.

Jankowski, N.W. and M. Van Selm (2000) 'Traditional Newsmedia Online: an Examination of Added Values', Communications 25(1): 85-101.

Jokisch, R. (1996) Logik der Distinktionen: zur Protologik einer Theorie der Gesellschaft. Opladen: Westdeutscher Verlag. URL (consulted July 2002): http://www.tuberlin.de/ society/Jokisch_Logik_Einleitung.htm 
Kawamoto, K. (1998) 'Making Sense of the New On-Line Environment in the Context of Traditional Mass Communications Study', in D. Borden and K. Harvey (eds), The Electronic Grapevine: Rumor, Reputation, and Reporting in the New On-Line Environment. Mahwah, NJ: Lawrence Erlbaum.

Kennedy, H. (2002) 'Postgraduate Multimedia Education: Practices, Themes and Issues', Infonomics Report, April, URL (consulted April 2002): http://cmd.infonomics.nl /reports.htm

Kenney, K., A. Gorelik and S. Mwangi (2000) 'Interactive Features of Online Newspapers', First Monday 5(1), URL (consulted December 2000): http:/ /firstmonday.org/issues/issue5_1/kenney/index.html

King, E. (1998) 'Redefining Relationships. Interactivity between News Producers and Consumers', Convergence 4(4): 26-32.

Kopper, G., A. Kolthoff and A. Czepek (2000) 'Research Review: Online Journalism a Report on Current and Continuing Research and Major Questions in the International Discussion', Journalism Studies 1(3): 499-512.

Kovach, B. and T. Rosenstiel (2001) The Elements of Journalism. New York: Crown.

Lasica, J. (2001) 'Blogging as a Form of Journalism', Online Journalism Review, 24 May, URL (consulted January 2003): http://www.ojr.org/ojr/workplace/1017958873.php

Loosen, W. and S. Weischenberg (2000) 'Online-Journalismus: Mehrwert durch Interaktivitaet?', in K. Altmeppen, H. Bucher and M. Loeffelholz (eds), Online journalismus: Perspektiven fuer Wissenschaft und Praxis, pp. 71-94. Wiesbaden: Westdeutscher Verlag.

Luege, T. (1999) 'Usage Patterns and Information Needs of Journalists on the Internet: an Empirical Study at USUS', report, Insitute for Communication Sciences Research, University of Munich.

Luenenbuerger-Reidenbach, W., J. Petersen and T. Wagensonner (2000) 'Media Studie 2000: Journalisten online', News Aktuell report, URL (consulted May 2002): http:/ /www.newsaktuell.de/de/media_events/media_studien/mediastudie/2000-01.html

McGuire, M., L. Stilborne, M. McAdams and L. Hyatt (2000) The Internet Handbook for Writers, Researchers, and Journalists. New York: Guilford Press.

Martikainen, M. (2000) 'Towards Dialogical Online Journalism', University of Tampere research report, URL (consulted May 2002): http://mansetori.uta.fi/report/ martikainen.pdf

Massey, B.L. and M.R. Levy (1999) “"Interactive” Online Journalism at Englishlanguage Web Newspapers in Asia', Gazette 61(6): 523-38.

Media Links (2001) 'Online Media Directory', Editor and Publisher Interactive Online Media Directory, URL (consulted May 2002): http//www.mediainfo.com

Meek, C. (2000) 'Online Journalism a Breed Apart, Say NetMedia Speakers', DotJournalism, 16 August, URL (consulted September 2000): http://www. journalism.co.uk/ezine_plus/dotjark/story135.shtml

Meier, K. (ed.) (2002) Internet-Journalismus (2nd ed). Konstanz: UVK.

Middleberg, D. and S. Ross (2002) 'The Eighth Annual Middleberg/Ross Survey of Media', Euro RSCG Middleberg report, URL (consulted May 2002): http: //www.middleberg.com/toolsforsuccess/fulloverview_2002.cfm

Nelson, T. (1999) 'Xanalogical Media: Needed Now More than Ever', ACM Computing Surveys paper, URL (consulted December 2000): http://www.xanadu.com /XANASTRUX/XuSum99.html

Neuberger, C. (2000) 'Renaissance oder Niedergang des Journalismus? Ein Forschungsueberblick zum Online-Journalismus', in K. Altmeppen, H. Bucher and 
M. Loeffelholz (eds), Online Journalismus: Perspektiven fuer Wissenschaft und Praxis, pp. 15-48. Wiesbaden: Westdeutscher Verlag.

Newhagen, J.E. and S. Rafaeli (1996) 'Why Communication Researchers Should Study the Internet: a Dialogue', Political Communication 46(1): 4-13.

Nielsen, J. and J. Morkes (1997) 'Concise, Scannable, and Objective: how to Write for the Web', Sun Microsystems paper, URL (consulted July 1998): http://www. useit.com/papers/webwriting/writing.html

Odlyzko, A. (2001) 'Content is not King', First Monday 2(6), URL (consulted February 2001): http://www.firstmonday.dk/issues/issue6_2/odlyzko/index.html

Outing, S. (2001) 'News sites Repeat the Mistakes of the Past: We Still Don't Recognize the Power of Interactivity', URL (consulted January 2003): http:

//www.editorandpublisher.com/editorandpublisher/features_columns/article_ display.jsp?vnu_content_id $=1461161$

Paul, N. (1995) 'Content: a Re-visioning. Production in the Electronic Products Newsroom', speech delivered to E\&P Interactive Newspapers Conference, URL (consulted January 2003): http://www.poynter.org/content/content_view.asp?id $=5684$

Pavlik, J. (1999) 'New Media and News: Implications for the Future of Journalism', New Media E Society 1(1): 54-9.

Pavlik, J. (2001) Journalism and New Media. New York: Columbia University Press.

Pavlik, J. and A. Clayton Powell, III (2001) 'New Media and Journalism and Mass Communication Education', paper presented at the online conference 'Best Practices in Journalism Education', Penn State University, Pennsylvania, PA, 25 March-7 April, URL (consulted April 2001): http://courses.worldcampus.psu.edu/welcome/best practices/

Perseus Publishers (2002) We've Got Blog: How Weblogs are Changing our Culture. Cambridge: MA: Perseus Publishing.

Platon, S. and M. Deuze (2003; in print) 'Indymedia Journalism: A Radical Way of Making, Selecting and Sharing News', Journalism 4(3).

Pleijter, A., F. Tebbe and L. Hermans (2002) Nieuwe journalisten door nieuwe bronnen?', Bikker Euro RSCG report, URL (consulted December 2002): http: //villa.intermax.nl/digiproject/content/onderzoek/startonderzoek.htm

Porteman, P. (1999) 'Multimedia-journalistiek: de journalist en het internet', Communicatie 28(2): 2-19.

Preecs, B. (2000) 'Open Source Journalism: an Alternate Strategy for Using the Internet to Empower Citizens and Strengthen Democracy', Make Your Own Media paper, URL (consulted May 2001): http://www.makeyourownmedia.org/osj.htm

Pryor, L. (2002) 'The Third Wave of Online Journalism', Online Journalism Review, 18 April, URL (consulted April 2002): http://www.ojr.org/ojr/future/1019174689 .php

Quinion, M. (1999) 'Prosumer', World Wide Words, URL (consulted June 2002): http: //www.quinion.com/words/turnsofphrase/tp-pro4.htm

Quinn, S. (1998) 'Newsgathering and the Internet', in M. Breen (ed.), Journalism: Theory and Practice, pp. 239-55. Paddington, NSW: Macleay Press.

Quinn, G. and B. Trench (2002) 'Online Newsmedia and Their Audiences', Mudia Work Package 3, July, URL (consulted November 2002): http://www.mudia.org/html/ resources/2_workpackages.htm

Reddick, R. and E. King (2001) The Online Journalist: Using the Internet and Other Electronic Resources (3rd ed). Fort Worth, TX: Harcourt Brace. 
Rorty, R. (1982) The Consequences of Pragmatism. Minneapolis, MN: University of Minnesota Press.

Rushkoff, D. (1997) Children of Chaos: Surviving the End of the World as We Know It. London: Flamingo.

Rushkoff, D. (2000) 'Ten Reasons to Be Happy After the Dot.com Crash', syndicated column, URL (consulted June 2001): http://www.rushkoff.com/TenReasons.html

Schudson, M. (1999a) 'Good Citizens and Bad History: Today's Political Ideals in Historical Perspective', paper presented at the Transformation of Civic Life conference, Nashville and Murfreesboro, TE, 12-13 November, URL (consulted June 2001): http://communication.ucsd.edu/people/f_schudson_nashville.html

Schudson, M. (1999b) 'What Public Journalism Knows About Journalism but Does Not Know About "Public", in T. Glasser (ed.), The Idea of Public Journalism, pp. 118-33. New York: Guilford Press.

Schultz, T. (1999) 'Interactive Options in Online Journalism: a Content Analysis of 100 U.S. Newspapers', Journal of Computer-Mediated Communication 5(1), URL (consulted January 2003): http://www.ascusc.org/jcmc/vol5/issue1/schultz.html

Shyam Sundar, S. (2000) 'The Internet - Multimedia Effects on Processing and Perception of Online News: a Study of Picture, Audio, and Video Downloads', Journalism Quarterly 77(3): 480-99.

Singer, J.B. (1997a) 'Changes and Consistencies: Newspaper Journalists Contemplate Online Future', Newspaper Research Journal 18(1): 2-18.

Singer, J.B. (1997b) 'Still Guarding the Gate? The Newspaper Journalist's Role in an On-line World', Convergence 3(1): 72-89.

Singer, J.B. (1998) 'Online Journalists: Foundation for Research into Their Changing Roles', Journal of Computer-Mediated Communication 4(1), URL (consulted November 1998): http://jcmc.huji.ac.il/vol4/issue1/singer.html

Steuer, J. (1992) 'Defining Virtual Reality: Dimensions Determining Telepresence', Journal of Communication 42(4): 73-93.

Toffler, A. (1981 [1980]) The Third Wave. London: Pan Books.

Verwey, P. (2000) 'CAR Revisited - ontwikkelingen in digitale journalistiek', Cahier 22, Utrecht School for Journalism, the Netherlands, URL (consulted December 2002): http://www.journalism.fcj.hvu.nl/dossier/bleeker/openingcahier22.htm

Ward, M. (2002) Journalism Online. Oxford: Focal Press.

Weaver, D.H. (ed.) (1998) The Global Journalist: News People Around the World. Cresskill, NJ: Hampton Press.

Weber, S. (2000) 'Ist eine integrative Theorie moeglich?', in M. Loeffelholz (ed.), Theorien des Journalismus, pp. 455-66. Opladen: Westdeutscher Verlag.

Weischenberg, S. and A. Scholl (1998) Journalismus in der Gesellschaft: Theorie, Methodologie und Empirie. Opladen: Westdeutscher Verlag.

White, C. (2002) 'Old School Journalism Alive and Well on the Web', DotJournalism, 7 February, URL (consulted January 2003): http://www.journalism.co.uk/ezine_plus/ dotjark/story446.shtml

Woodstock, L. (2000) 'Public Journalism's Talking Cure: an Analysis of the Movement's 'Problem' and 'Solution' Narratives', Journalism 3(1): 37-55.

Zoch, L. (2001) 'Video in Print: Who is Doing What?', presentation at the WAN 54th World Newspaper Congress, Hong Kong, URL (consulted May 2002): http: //www.wan-press.org/ce/previous/2001/congress.forum/forum/zoch.html

MARK DEUZE is Assistant Professor at the Department of Communication, and Researcher at the Amsterdam School of Communications Research (ASCoR), University of Amsterdam. The 
author received his BA in journalism at the Tilburg School for Journalism, the Netherlands, MPhil in history and communication studies at the Rand Afrikaans University in Johannesburg, and $\mathrm{PhD}$ in social sciences at the University of Amsterdam. Publications include articles in Journalism Quarterly, Journalism Educator, European Journal of Communication and First Monday. From 2002 to 2003, Deuze is a Fulbright Scholar at the University of Southern California's Annenberg School for Communication.

Address: ASCoR, Kloveniersburgwal 48, 1012 CX Amsterdam, the Netherlands. [email: mark.deuze@reporters.net] 